Acta Technologica Agriculturae 2

Nitra, Slovaca Universitas Agriculturae Nitriae, 2015, pp. 36-41

\title{
STUDY OF ENERGY CONSUMPTION OF POTATO SLICES DURING DRYING PROCESS
}

\author{
Negar HAFEZI*, Mohammad Javad SHEIKHDAVOODI, Seyed Majid SAJADIYE \\ Shahid Chamran University of Ahvaz, Ahvaz, Iran
}

\begin{abstract}
One of the new methods of food drying using infrared heating under vacuum is to increase the drying rate and maintain the quality of dried product. In this study, potato slices were dried using vacuum-infrared drying. Experiments were performed with the infrared lamp power levels 100, 150 and $200 \mathrm{~W}$, absolute pressure levels 20, 80, 140 and $760 \mathrm{mmHg}$, and with three thicknesses of slices 1,2 and $3 \mathrm{~mm}$, in three repetitions. The results showed that the infrared lamp power, absolute pressure and slice thickness have important effects on the drying of potato. With increasing the radiation power, reducing the absolute pressure (acts of vacuum) in the dryer chamber and also reducing the thickness of potato slices, drying time and the amount of energy consumed is reduced. In relation to thermal utilization efficiency, results indicated that with increasing the infrared radiation power and decreasing the absolute pressure, thermal efficiency increased.
\end{abstract}

Keywords: potato, drying, infrared vacuum, energy consumed, thermal utilization efficiency

Potato (Solanum tuberosum L.) is one of the unique and most potential crops having high productivity, supplementing the major food requirement in the world. It is rich in carbohydrates, proteins, phosphorus, calcium, vitamin $\mathrm{C}$, $\beta$-carotene and has high protein calorie ratio. Amongst the world's important food crops, potato is the fourth important food crop after wheat, rice and maize because of its great yield potential and high nutritive value. The ratio of protein to carbohydrate is higher in potato than in many cereals and other tuber crops (Faisal et al., 2013). Drying is generally carried out for two main reasons, the first one to reduce the water activity which eventually increases the shelf life of food and the second one to reduce the weight and bulk of food for cheaper transport and storage (Hatamipour et al., 2007).

Drying of food products has been a very important industrial sector for many years. Drying is the most energyintensive process in the food industry. Therefore, new drying techniques and dryers must be designed and studied to minimize the energy cost in the drying process (Kocabiyik and Tezer, 2009). Microbial activities are not active when the moisture content of a product is below $10 \%$. Hence, harvested vegetables must be stored dry $(5 \%$ moisture content on wet basis) to prevent attack and deterioration by activities of microorganisms and fungi (FAO, 1981). Considering the fact that the highest energy consumption in agriculture is associated with drying operations, different drying methods can be evaluated to determine and compare the energy requirements for drying a particular product. Thermal drying operations are found in almost all industrial sectors and are known, according to various estimates, to consume $10-25 \%$ of the national industrial energy in the developed world (Kemp, 2012). In order to reduce the energy requirement during the dehydration process and also to minimize the quality degradation of dried products, it is necessary to select an efficient drying system. Increasing concern for product quality and the need for minimized processing and energy costs have led to a more detailed study and understanding of drying of food materials. This has also revolutionized the design and development of drying systems (Umesh Hebbar et al., 2004). Dryers are one of the most important equipment in food processing industries. Many dryers have been developed and used to dry agricultural products in order to improve their storage conditions. Most of the dryers use either an expensive source of energy such as electricity or a combination of solar energy and other forms of energy (Ehiem et al., 2009). In infrared drying, special infrared lamps are used to extract moisture from the material being dried. In this method, the air surrounding wet matter flows using a suction device (vacuum pump) to remove humidity released by the matter from its vicinity in order for it to face less resistance while avoiding material surface saturation with dump. Infrared radiation drying has unique characteristics of energy transfer mechanism. During infrared radiation, the energy in the form of electromagnetic wave is absorbed directly by the product without loss to the environment, leading to considerable energy savings. Energy analyses have been conducted for different drying methods and conditions for products, such as carrots (Nazghelichi et al., 2010), mushrooms slices (Motevali et al., 2011a), sour pomegranates (Motevali et al., 2011b), and red pepper (Kowalski and Mierzwa, 2011). In the vacuum drying method due to lack of oxygen in dryer ambiance and unwanted reduction of reactions in food, the

Contact address: $\quad$ *Negar HAFEZI, MSc. Student, Department of Mechanics of Agricultural Machinery and Mechanization, Faculty of Agriculture, Shahid Chamran University of Ahvaz, Ahvaz, Iran, e-mail: nhafezi05@yahoo.com 
quality of dried food in this method is higher than the others (Motevali et al., 2011b). Also applying vacuum in food drying causes expansion of air and vapour and creates puff state in the matter. Due to the high energy consumption in this method, vacuum drying can be used for highly sensitive and high value-added products (Motevali et al., 2011a). For drying under vacuum (or vacuum drying), moisture within the product being dried evaporates at lower temperatures (lower than $100{ }^{\circ} \mathrm{C}$ ) giving better product quality, especially in the cases of foods or agricultural products, which are heat-sensitive in nature. When the advantages of the two dying methods are combined, energy efficiency of the drying process is enhanced and degradation of dried product quality is also reduced. The present work is aimed at studying the effects of drying kinetics on energy consumption, specific energy consumption and thermal utilization efficiency of potato slices by infrared radiation under vacuum.

\section{Material and methods}

\section{Experimental set-up}

A laboratory scale vacuum-infrared dryer, developed at the Agricultural Machinery and Mechanization Engineering Laboratory, Shahid Chamran University (Iran) has been used. A schematic diagram of the

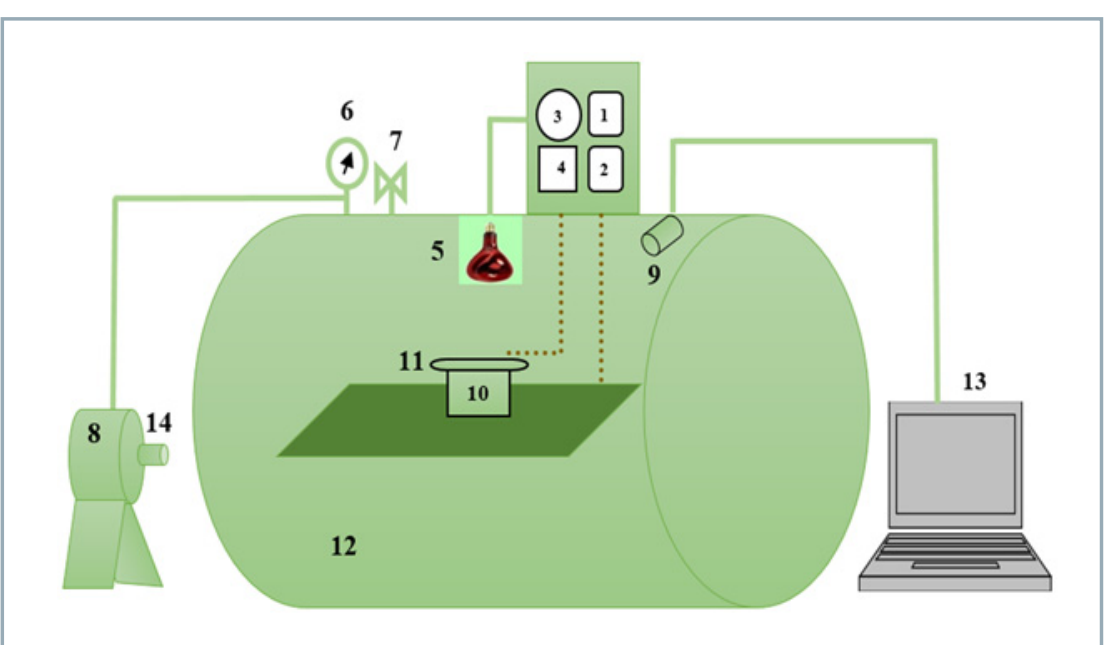

Figure 1 A schematic diagram of a vacuum-infrared drying system

1 - humidity sensor, 2 - thermocouples, 3 - infrared lamp power controller, 4 voltmeter, 5 - infrared lamp, 6 - vacuum gauge, 7 - vacuum break-up valve, 8 - vacuum pump, 9 - camera, 10 - electronic weight scale, 11 - sample tray 12 - drying chamber, 13 - laptop, 14 - air outlet duct using an electronic weight scale (Lutron, GM-1500P, Taiwan) with the accuracy of $\pm 0.05 \mathrm{~g}$. Temperatures of the drying chamber and of the drying sample were measured continuously using thermocouples (SAMWONENG, SU-105KRR). At the beginning of experiments, relative humidity and temperatures of the drying chamber were set on $35 \%$ and $50{ }^{\circ} \mathrm{C}$. The drying experiments were performed until the sample moisture content of $6-7 \%(\mathrm{wb})$ was obtained.

\section{Theoretical principle}

To find a suitable mathematical model, moisture content data at different thickness, absolute pressure levels and infrared power were converted to the moisture ratio ( $M R$, dimensionless) expression by using the following equation.

$$
M R=\frac{M_{t}-M_{e}}{M_{o}-M_{e}}
$$

where:

$M R$ - moisture content ratio

$M_{t}$ - moisture content at any drying time on wet basis

$M_{e}$ - equilibrium moisture content on wet basis

$M_{0}$ - initial moisture content on wet basis

\section{Evaluation of energy consumption}

In this study, the energy consumption of the drying process came from the electric energy consumed by the operation of the vacuum pump and the infrared lamp. Energy consumption by the vacuum pump can be calculated using Eq. (2):

$$
E_{1}=\int_{t=1}^{T} V \times I \times \Delta t \times \cos \varphi
$$

where:

$E_{1} \quad$ - power consumed by the pump (kWh)

$V$ - nominal pump voltage (kW)

I - electric current intensity in the pump

$T \quad$ - drying time (h)

$\varphi$ - electric power factor (a fixed amount)

The rate of energy expenditure by the infrared lamp is constant at any given time and is obtained using Eq. (3). The infrared lamp power in this dryer is $250 \mathrm{~W}$ at $230 \mathrm{~V}$ : 


$$
E_{2}=\int_{t=1}^{T} V \times I \times \Delta t
$$

where:

$E_{2}$ - represents the energy consumed by the infrared lamp

$V \quad$ - lamp voltage (V)

$I$ - electric current intensity in the lamp

$T \quad$ - drying time (h)

$$
E_{t}=E_{1}+E_{2}
$$

where:

$E_{t} \quad$ - total energy needed for drying at each condition of the experiments $(\mathrm{kWh})$

\section{Evaluation of specific energy consumption}

Specific energy consumption was defined as the energy required for removing a unit mass of water in drying the potato slice that is calculated using Eq. (5):

$$
E_{s}=\frac{E_{t}}{m_{w}}
$$

where:

$E_{s} \quad$ - specific energy requirement $\left(\mathrm{kWh} \mathrm{kg}^{-1}\right)$

$m_{w}$ - the amount of initial weight of the product $(\mathrm{kg})$

\section{Evaluation of thermal utilization efficiency}

Thermal utilization efficiency is defined as the ratio of latent moisture evaporation heat of sample to the amount of energy required to evaporate moisture from free water (Umesh Hebbar et al., 2004). Considering that the highest energy consumption in agriculture is related to drying the product, different drying methods can be evaluated to calculate and compare the energy requirements for drying a particular product.

The vacuum-infrared drying efficiency was calculated as the ratio of the heat energy utilized for evaporating water from the sample to the heat supplied by the vacuuminfrared dryer (Soysal, 2004):

$$
\eta=\frac{m_{w} \times \lambda_{w}}{3600 \times E_{t}} \times 100
$$

where:

$\eta \quad$ - vacuum-infrared drying efficiency (\%)

$m_{w}$ - the initial weight of the product $(\mathrm{kg})$

$\lambda_{w}$ - the latent heat of vaporization of water $\left(\mathrm{kJ} \mathrm{kg}^{-1}\right)$. The latent heat of vaporization of water at the evaporating temperature of $100{ }^{\circ} \mathrm{C}$ was taken as $2257 \mathrm{~kJ} \mathrm{~kg}^{-1}$ (Hayes, 1987)

For statistical analysis, a factorial experiment based on randomized complete block design with three replications was used. Statistical analyses were performed using MSTATC and SPSS16 so the differences between the means were compared by Duncan's test.

\section{Results and discussion}

Results of the evaluation of energy consumption of potato slices drying are shown in Table 1. Statistical analysis (ANOVA, post-hoc Duncan) showed that thickness and infrared power at the error level of $1 \%$ and absolute pressure at the error level of $5 \%$ parameters had statistically significant influence on energy consumption values of dried potato slices.

Figure 2 up to Figure 4 show the amount of energy needed by the vacuum-infrared dryer to dry the potato slices. The use of vacuum in conjunction with infrared radiation drying increased the energy consumption in comparison to merely infrared drying. The maximum and minimum energy consumption values were calculated to be $6.43 \mathrm{MJ}$ and $2.053 \mathrm{MJ}$ for the infrared power of $100 \mathrm{~W}$ with absolute pressure level $760 \mathrm{mmHg}$ (without acts of vacuum) at the slice thickness of $3 \mathrm{~mm}$ and the infrared power of $150 \mathrm{~W}$ with the absolute pressure of $20 \mathrm{mmHg}$ at the slice thicknesses of $1 \mathrm{~mm}$, respectively.

Table 1 Analysis of variance of the effect of slice thickness, absolute pressure and infrared power on the amount of consumption energy in drying process

\begin{tabular}{|l||c|c|c|c|c|}
\hline \multicolumn{5}{|l|}{ Tests of Between - Subjects Effects } \\
\hline \hline Dependent variable: consumption energy & Sum of squares & df & Mean square & F & Sig. \\
\hline Source & 45.439 & 2 & 22.719 & 22.746 & 0.000 \\
\hline Thickness & 7.050 & 3 & 2.350 & 2.353 & 0.039 \\
\hline Absolute pressure & 39.907 & 2 & 19.953 & 19.977 & 0.000 \\
\hline Infrared power & 0.911 & 6 & 0.152 & 0.152 & 0.988 \\
\hline Thickness $\times$ absolute pressure & 1.015 & 4 & 0.254 & 0.254 & 0.906 \\
\hline Thickness $\times$ infrared power & 8.566 & 6 & 1.428 & 1.429 & 0.215 \\
\hline Absolute pressure $\times$ infrared power & 2.181 & 12 & 0.182 & 0.182 & 0.999 \\
\hline Thickness $\times$ absolute pressure $\times$ infrared power & 71.915 & 72 & 0.999 & - & - \\
\hline Error & 1807.999 & 108 & - & - & - \\
\hline Total & 176.983 & 107 & - & - & - \\
\hline Corrected total & & & - \\
\hline
\end{tabular}

a. R squared $=0.594$ (adjusted $R$ squared $=0.369$ ) 


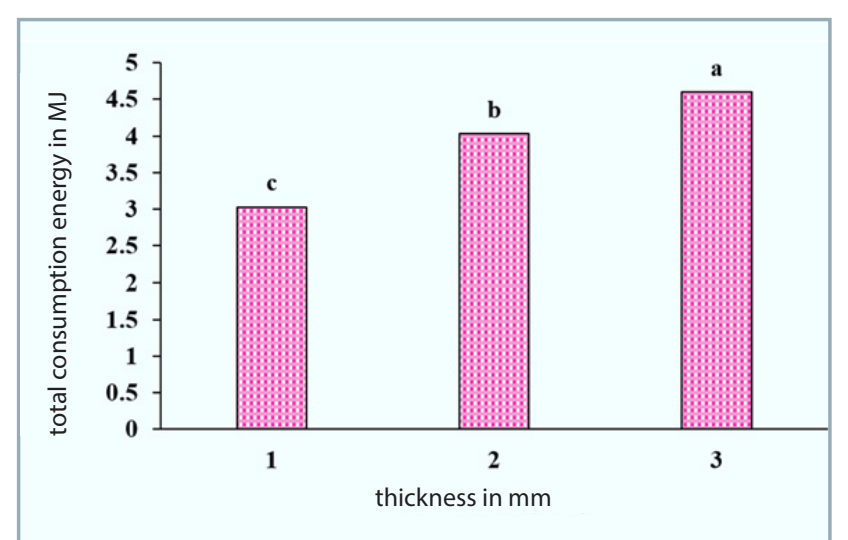

Figure 2 The effect of slice thickness on the consumption energy of potato slices during drying process

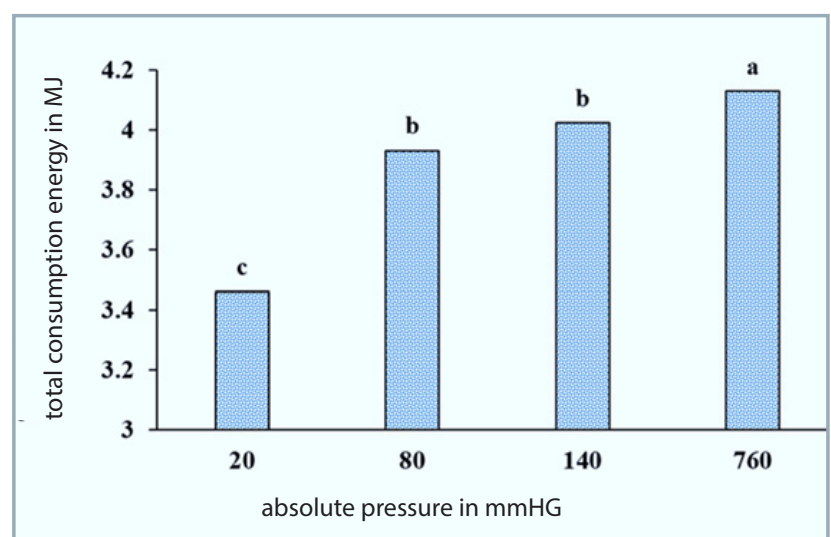

Figure 3 The effect of absolute pressure on the consumption energy of potato slices during drying process

According to Table 2 and statistical analysis (ANOVA, post-hoc Duncan), results showed that the factor of thickness was not statistically significant on specific energy. The effect of absolute pressure $(p<0.05)$ and infrared

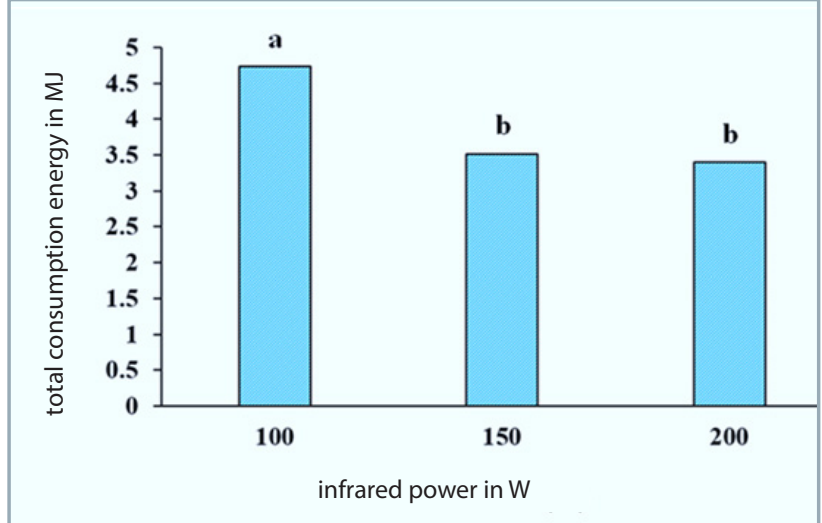

Figure 4 The effect of infrared power on the consumption energy of potato slices during drying process

power $(p<0.01)$ parameters and also the interaction of absolute pressure and infrared power $(p<0.05)$ had statistically significant influence on the specific energy of dried potato slices.

Figure 5 shows the effect of specific energy on the interaction between absolute pressure and infrared power. The minimum and maximum energy requirements for drying of potato slices were also determined as $5.3 \mathrm{kWh} \mathrm{kg}^{-1}$ $\mathrm{H}_{2} \mathrm{O}$ and $185.14 \mathrm{kWh} \mathrm{kg}^{-1} \mathrm{H}_{2} \mathrm{O}$ for the infrared power of $200 \mathrm{~W}$ with the absolute pressure of $80 \mathrm{mmHg}$ at the thickness of $1 \mathrm{~mm}$ and the infrared power of $100 \mathrm{~W}$ with the absolute pressure level $760 \mathrm{mmHg}$ (without acts of vacuum) at the slice thickness of $3 \mathrm{~mm}$, respectively.

According to Table 3 and statistical analysis (ANOVA, post-hoc Duncan), results showed that the factor of absolute pressure had statistically significant effect at the error level $5 \%$ on thermal utilization efficiency. Also the effect of interaction of absolute pressure and infrared power had statistically significant effect at the error level $5 \%$ on the thermal utilization efficiency of dried potato slices. The drying efficiency of potato slices varied between $2.39 \%$ and $31.64 \%$.

Table 2 Analysis of variance of the effect of slice thickness, absolute pressure and infrared power on the amount of specific energy in drying process

\begin{tabular}{|c|c|c|c|c|c|}
\hline \multicolumn{6}{|c|}{ Tests of Between - Subjects Effects } \\
\hline \multicolumn{6}{|l|}{ Dependent variable: specific energy } \\
\hline Source & Sum of squares & df & Mean square & $\mathbf{F}$ & Sig. \\
\hline Thickness & 12010.012 & 2 & 6005.006 & 1.099 & 0.339 \\
\hline Absolute pressure & 32501.206 & 3 & 10833.735 & 1.982 & 0.024 \\
\hline Infrared power & 71015.843 & 2 & 35507.922 & 6.496 & 0.003 \\
\hline Thickness $\times$ absolute pressure & 7084.656 & 6 & 1180.776 & 0.216 & 0.971 \\
\hline Thickness $\times$ infrared power & 8863.932 & 4 & 2215.983 & 0.405 & 0.804 \\
\hline Absolute pressure $\times$ infrared power & 65196.766 & 6 & 10866.128 & 1.988 & 0.043 \\
\hline Thickness $\times$ absolute pressure $\times$ infrared power & 73200.395 & 12 & 6100.033 & 1.116 & 0.361 \\
\hline Error & 393568.309 & 72 & 5466.227 & - & - \\
\hline Total & 5934711.864 & 108 & - & - & - \\
\hline Corrected total & 663411.120 & 107 & - & - & - \\
\hline
\end{tabular}

a. $\mathrm{R}$ squared $=0.407$ (adjusted $\mathrm{R}$ squared $=0.118$ ) 
Table 3 Analysis of variance of the effect of slice thickness, absolute pressure and infrared power on thermal utilization efficiency in drying process

\begin{tabular}{|l||c|c|c|c|c|}
\hline \multicolumn{5}{|c|}{ Tests of Between - Subjects Effects } \\
\hline \hline Dependent variable: thermal utilization efficiency & Sum of squares & df & Mean square & F & Sig. \\
\hline Source & 6.911 & 2 & 3.456 & 1.400 & 0.253 \\
\hline Thickness & 976.329 & 3 & 325.443 & 131.880 & 0.013 \\
\hline Absolute pressure & 8.238 & 2 & 4.119 & 1.669 & 0.196 \\
\hline Infrared power & 9.908 & 6 & 1.651 & 0.669 & 0.675 \\
\hline Thickness $\times$ absolute pressure & 7.354 & 4 & 1.838 & 0.745 & 0.565 \\
\hline Thickness $\times$ infrared power & 43.617 & 6 & 7.269 & 2.946 & 0.025 \\
\hline Absolute pressure $\times$ infrared power & 25.171 & 12 & 2.098 & 0.850 & 0.600 \\
\hline Thickness $\times$ absolute pressure $\times$ infrared power & 177.677 & 72 & 2.468 & - & - \\
\hline Error & 2258.149 & 108 & - & - & - \\
\hline Total & 1255.205 & 107 & - & - & - \\
\hline Corrected total & & & & - \\
\hline
\end{tabular}

a. $\mathrm{R}$ squared $=0.858$ (adjusted $\mathrm{R}$ squared $=0.790$ )

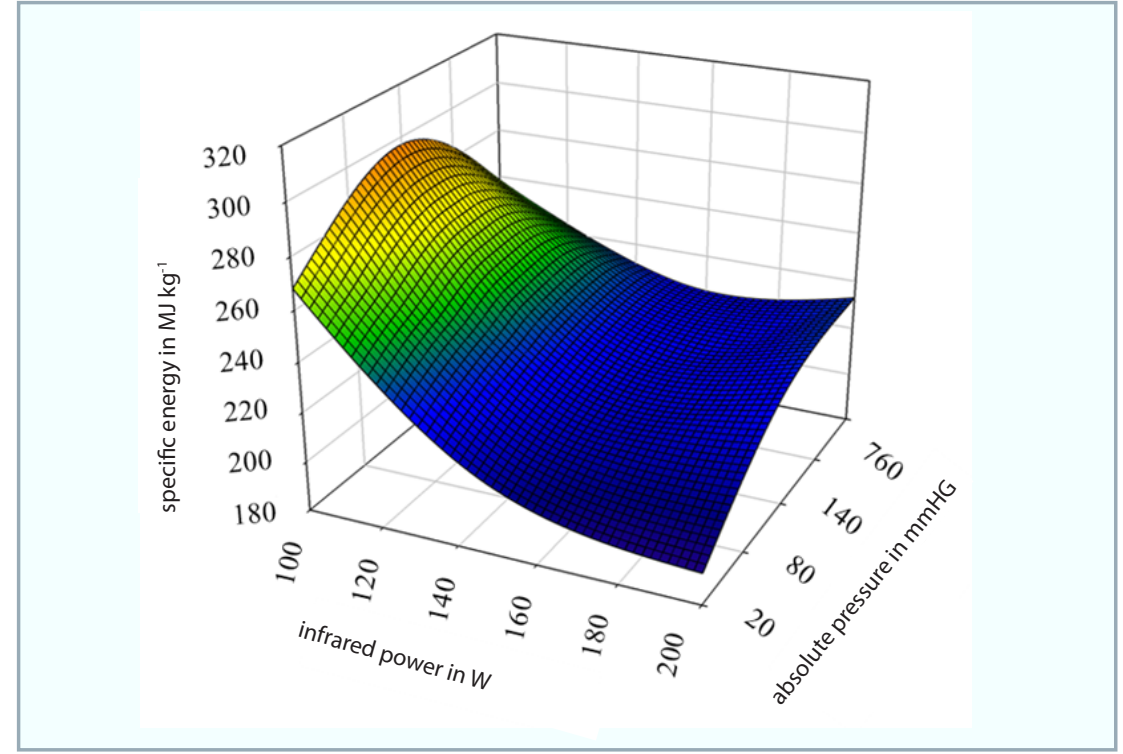

Figure 5 The interaction between absolute pressure and infrared power on the specific energy of potato slices during drying

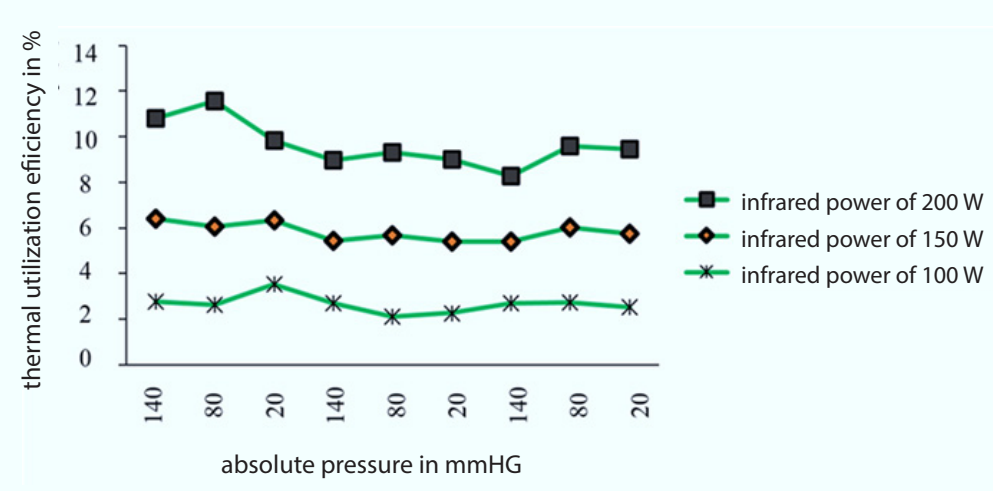

Figure 6 The interaction between absolute pressure and infrared power on the thermal utilization efficiency of potato slices during drying process
Figure 6 shows the average thermal utilization efficiency in this drying method on the interaction between absolute pressure and infrared power. Regardless of the absolute pressure of $760 \mathrm{mmHg}$ (atmospheric conditions), maximum thermal utilization efficiency has been related to the infrared power of $200 \mathrm{~W}$ at the absolute pressure of $80 \mathrm{mmHg}$ and the lowest amount of efficiency has been related to the power of $100 \mathrm{~W}$ at the same level of absolute pressure. Overall, the results suggest that with the increase of infrared radiation power and the decrease of absolute pressure drying time and consequently energy consumption decreased and thermal efficiency increased.

\section{Conclusion}

The drying kinetics of the potato slices was investigated in the vacuuminfrared dryer. Moisture content and drying rates were influenced by infrared power, absolute pressure and thickness. Results showed that drying time decreased with the increase of infrared radiation power and the decrease of absolute pressure (acts of vacuum). The minimum energy consumption was observed in the infrared-vacuum drying method (150 W with the absolute pressure of $20 \mathrm{mmHg}$ ), while the maximum energy consumption occurred in merely infrared drying (100 W with atmospheric conditions). 


\section{References}

AOAC. 1990. Official Methods of Analysis. No. 934-06. Washington, DC : Association of Official Analytical Chemists, 1990.

EHIEM, J. C. - IRTWANGE, S. V. - OBETTA, S. E. 2009. Design and development of an industrial fruit and vegetable dryer. In Research Journal of Applied Sciences, Engineering and Technology, vol. 1, 2009, no. 2, pp. 44-53.

FAISAL, S. H. - RUHI, T. - VISHAL, K. 2013. Performance evaluation and process optimization of potato drying using hot air oven. In Journal of Food Processing and Technology, vol. 4, 2013, no. 10, pp. 1-9.

FAO. 1981. Food loss prevention in perishable crop. Food and Agriculture Organization of the United Nations.

HATAMIPOUR, M. S. - KAZEMI, H. H. - NOORALIVAND, A. NOZARPOOR, A. 2007. Drying characteristics of six varieties of sweet potatoes in different dryers. In Food Bioproducts Process, vol. 85, 2007, no. C3, pp. 171-177.

HAYES, G. D. 1987. Food Engineering Data Handbook. England : Longman Scientific and Technical, 1987.

KEMP, I. C. 2012. Fundamentals of energy analysis of dryers. Modern Drying Technology. In Energy Savings, vol. 4, 2012, no. 1, p. 1-46.

KOCABIYIK, H. - TEZER, D. 2009. Drying of carrot slices using infrared radiation. In International Journal of Food Science and Technology, 2009, no. 44, pp. 953-959.
KOWALSKI, S. J. - MIERZWA, D. 2011. Hybrid drying of red bell pepper: energy and quality issues. In Drying Technology, 2011, no. 29, pp. 1195-1203.

MOTEVALI, A. - MINAEI, S. - KHOSHTAGAZA, M. H. 2011b. Evaluation of energy consumption in different drying methods. In Energy Conversion and Management, vol. 52, 2011, no. 2, pp. 1192-1199.

MOTEVALI, A. - MINAEI, S. - KHOSHTAGHAZA, M. H. - AMIRNEJAT, H. 2011a. Comparison of energy consumption and specific energy requirements of different methods for drying mushroom slices. In Energy, 2011, no. 36, pp. 6433-6441.

NAZGHELICHI, T. - KIANMEHR, M. H. - AGHBASHLO, M. 2010. Thermodynamic analysis of fluidized bed drying of carrot cubes. In Energy, vol. 35, 2010, no. 12, pp. 4679-4684.

SOYSAL, A. 2004. Microwave drying characteristics of parsley. In Biosystems Engineering, vol. 89, 2004, no. 2, pp. 167-173.

UMESH HEBBAR, H. - VISHWANATHAN, K. H. - RAMESH, M. N. 2004. Development of combined infrared and hot air dryer for vegetables. In Journal of Food Engineering, vol. 65, 2004, no. 4, pp. 557-563. 